\title{
Mental health during COVID-19 lockdown in India: Role of psychological capital and internal locus of control
}

\author{
Priya Alat $^{1}$ (D) $\cdot$ Sitanshu Sekhar $\operatorname{Das}^{1}$ (D) $\cdot$ Alisha Arora $^{2}$ (D) $\cdot$ Amrit Kumar Jha ${ }^{3,4}$ (D) \\ Accepted: 16 February 2021 / Published online: 12 March 2021 \\ (C) The Author(s), under exclusive licence to Springer Science+Business Media, LLC part of Springer Nature 2021
}

\begin{abstract}
The Government of India implemented a nationwide lockdown from March 24, 2020 in response to the Coronavirus disease (COVID-19) outbreak. This study examines the effects of two positive psychological resources on the mental health of Indian citizens during the early days of the lockdown. The effects of psychological capital (PsyCap) and internal locus of control on psychological distress of people via affect balance were tested. Data were collected through an online survey from 667 participants. Psychological distress was assessed using the GHQ-12, and affect balance was assessed as the preponderance of positive over negative affect. Results reveal that psychological capital and internal locus of control were negatively associated with psychological distress. In addition, affect balance mediated the relationship between psychological capital and psychological distress and the relationship between internal locus of control and psychological distress. Thus, both the psychological resources through affect balance acted as buffers protecting people from mental health deterioration during COVID-19 lockdown. However, the direct and indirect effects of psychological capital on psychological distress is stronger than that of internal locus of control. Implications and directions for future research are discussed.
\end{abstract}

Keywords COVID-19 $\cdot$ Lockdown $\cdot$ Psychological distress $\cdot$ Positive and negative affect $\cdot$ Psychological capital $\cdot$ Internal locus of control

\section{Introduction}

The COVID-19 pandemic is a one of a kind event that has altered the way of life. One of the major challenges during COVID-19 has been the phenomenon of physical distancing (Le et al., 2020; Okabe-Miyamoto, Folk, Lyubomirsky, \& Dunn, 2020; Tran et al., 2020). Since the early months of 2020, stringent lockdowns imposing restrictions on travel and social gathering became common in several countries. India was among the first nations to restrict international travels in January 2020 (DNA Web Team, 2020). This was gradually followed by regional lockdowns and curfews in severely affected areas of the country. On 22 March 2020, a

Sitanshu Sekhar Das

sitanshusekhardas@gmail.com

1 Rajagiri Business School, Rajagiri Valley, Kakkanad, Kochi, Kerala 682039, India

2 Central Institute of Psychiatry, Ranchi, India

3 Indian Institute of Technology Kharagpur, Kharagpur, India

4 C. M. College, Lalit Narayan Mithila University, Darbhanga, India 14-h voluntary lockdown was observed (The Indian Express, 2020). Finally, the Government of India announced a 21-day nationwide lockdown from 24 March, 2020 (when the data was collected the lockdown was declared for 21 days, after that it was further extended till May 3, 2020). Workplaces, educational institutions, places of worship, shopping centers, and other commercial centers were to remain closed and railways and airlines services suspended. People were allowed to go out only for buying essential commodities during scheduled hours or else face punitive measures. The lockdown of such a scale and strictness, in spite of the adverse effects on the economy, hinted at the severity of the crisis.

Lockdowns, though potentially effective in controlling disease outbreaks, can be unsettling for people (Madhav et al., 2017). Restrictions on day-to-day functioning, separation from loved ones, impending economic crises, impact on education and career, and lack of recreational activities, along with continuous hygiene practices, can cause mental health problems in anyone experiencing confinement (Pan American Health Organization, 2009; Vieira, Franco, Restrepo, \& Abel, 2020). Furthermore, the term 'lockdown' has negative connotations being associated with imprisonment and infringement of personal liberty (Arora, Jha, Alat, 
\& Das, 2020; Pfefferbaum \& North, 2020). During COVID19 lockdowns too, the disruption of personal and professional lives have been associated with several mental health issues (Odriozola-González, Planchuelo-Gómez, Irurtia, \& de LuisGarcía, 2020; Pandey et al., 2020; Zhang, Wang, Rauch, \& Wei, 2020). The most commonly reported were feelings of loss of control, depression, and anxiety- and stress-related conditions such as panic disorder, worry about own health and that of loved ones, and difficulty in sleeping or concentrating (Centers for Disease Control and Prevention, 2020; Le et al., 2020; Pierce et al., 2020; Roy et al., 2020; Tee et al., 2020; Wang et al., 2020a; Wang et al., 2020b; Xiong et al., 2020). In India, even before the nationwide lockdown was declared, people had been exhibiting anxiety-related behaviors in anticipation of a long-term shutdown. This was evident in panic buying and mass exodus of people toward their hometown since the beginning of March 2020 (Mukherjee, Bailay, \& Shrivastava, 2020).

The COVID-19 mental health discourse indicates that, as stressors cannot be avoided due to the pandemic mitigation measures, maintaining positivity can prevent mental health problems (Hagger, Keech, \& Hamilton, 2020; Shacham et al., 2020). In previous disease outbreaks of SARS (20022003) and HIV-AIDS, positive psychological resources such as locus of control, optimism, and resilience were found to be associated with both well-being and reduced mental illness (Chakraborty, 2020; Folkman \& Moskowitz, 2000; Taylor, Helgeson, Reed, \& Skokan, 1991). In line with such findings, this paper examines the associations of two positive psychological resources, PsyCap and internal locus of control with mental health during COVID-19 lockdown in India. These resources enable positive reappraisal and other forms of adaptive coping during adverse events (Luthans, Youssef, \& Avolio, 2007) and are positively associated with well-being and negatively associated with mental health problems. This research examines whether individuals high in PsyCap and internal locus of control experience less psychological distress due to affect balance or the experience of more positive over negative emotions. Such an examination would be useful as presently people are experiencing more negative and less positive emotions which is causing psychological distress (Government of India, 2020; Wang et al., 2020). Furthermore, to the best of our knowledge, except one study (Kim, 2020), the role of these resources has not yet been examined in relation to mental health issues during COVID19 (Rajkumar, 2020; Vindegaard \& Benros, 2020).

\section{Conceptual Framework}

\section{PsyCap and Psychological Distress}

PsyCap is a positive psychological state of development characterized by hope, efficacy, resilience, and optimism (Luthans et al., 2007). Hope refers to perseverance toward goals and the use of multiple pathways toward the attainment of goals. Selfefficacy is the belief in one's own ability to perform various tasks. Resilience enables individuals to "bounce back" from episodes of potential/actual failure. Optimism refers to a positive perspective toward life events and expectancy of positive outcomes. PsyCap is a resource caravan combining these four resources (Carmona-Halty, Salanova, Llorens, \& Schaufeli, 2019). PsyCap has both negative associations with mental ill-health and positive associations with well-being (Finch, Farrell, \& Waters, 2020) among various segments of population such as defense personnel (Krasikova, Lester, \& Harms, 2015; Schaubroeck, Riolli, Peng, \& Spain, 2011), disaster survivors (Fang, Prayag, Ozanne, \& de Vries, 2020), and students (Finch et al., 2020).

Individuals high in PsyCap perceive sufficient resources to strive through adversities (Schaubroeck et al., 2011). They are thus able to positively reappraise adverse situations and reframe goals to address the demands of changed circumstances (Luthans et al., 2007; Manuti, 2014). During lockdowns, rather than being passively locked inside homes, people were engaging in various activities which can be viewed as expressions of PsyCap resources (Vibha, Prabhu, Kamath, \& Pai, 2020). People were cheering each other through music and dance from their balconies (Locker \& Hoffman, 2020), sharing humorous content and stories of recoveries on social media (WHO, 2020), reaching out to socioeconomically disadvantaged sections, frontline workers, and isolated individuals (Ajmal, 2020), and pursuing old hobbies. Thus PsyCap can enable individuals to engage in contextually relevant activities to adapt to the changed circumstances rather than dwelling on the negative implications of traumatic events (Schaubroeck et al., 2011; Vibha et al., 2020). Furthermore, individuals with high PsyCap engage in more health promoting behaviors and gather more social support (Fang et al., 2020; Krasikova et al., 2015). This might make adverse situations appear less threatening (Manuti, 2014), and lessen anxiety about health risks, economic difficulties, and isolation during the lockdown (Centers for Disease Control and Prevention, 2020). Hence, it is expected that:

H1: PsyCap negatively associates with psychological distress.

\section{Internal Locus of Control and Psychological Distress}

Locus of control is a control belief. Individuals with an internal locus of control perceive life outcomes to be the result of their own actions and personal characteristics, whereas individuals with external locus of control perceive life outcomes to be under the control of external forces such as situation and luck (Rotter, 1966). The beliefs of control over consequences 
influence the actions people take to influence their conditions (McClure, Walkey, \& Allen, 1999). Individuals with internal locus of control consider it their personal responsibility to influence life circumstances through proactive behaviors and personal choices (Heinstrom, 2010; Wallston, 2015). Even during disasters, when exercising control over global causes is not possible, individuals with internal locus of control engage in precautionary behaviors such as buying insurance (McClure et al., 1999). In the current pandemic too the scope of personal control is low as the spread of infection also depends upon the behaviors of others. However, individuals with internal locus of control can engage in precautionary behaviors like washing hands, using masks, maintaining social distance to protect themselves from chances of contagion. Such efforts may make these unpredictable situations appear less threatening (Heinstrom, 2010). Hence, it is expected that:

$\mathrm{H} 2$ : Internal locus of control negatively associates with psychological distress.

\section{Affect Balance as Mediator between (a) PsyCap and (b) Internal Locus of Control and Psychological Distress}

Affect is an umbrella term that encompasses a range of dispositions, moods, and emotions (Niven, 2013). Positive affect represents pleasurable and positive experiences and includes emotions such as joy, contentment, and love. Negative affect includes a range of negative mood states, including fear, hostility, scorn, and disgust. Affect balance is a preponderance of positive affect over negative affect, and is a component of subjective well-being (Diener \& Lucas, 1999). According to the dual continua model, affect balance is a correlated but separate continua from psychological distress and has an adaptive role during stress (Diehl \& Berg, 2011; Keyes, Dhingra, \& Simoes, 2010; Machado, de Oliveira, Peregrino, \& Cantilino, 2019; Westerhof \& Keyes, 2010). It intervenes the rumination process and enhances efficient problem solving and thus prevents mental ill-health (Folkman \& Moskowitz, 2000; Klonowicz, 2001; Moors, 2017; Trompetter, de Kleine, \& Bohlmeijer, 2017).

Positive psychological resources can be a source of affect balance during adverse events. These resources influence people's appraisal of their relationship to the environment. Such appraisals, according to the cognitive appraisal theory, decide the intensity and kind of emotions that will be generated (Avey, Wernsing, \& Mhatre, 2011; Folkman \& Moskowitz, 2000; Lazarus, 1991; Moors, 2017). Furthermore, personal resources can enhance positive affect when they enable individuals to strive and adapt their goals according to the situations (Diener \& Fujita, 1995; Hobfoll, 2002; Smith, Tooley, Christopher, \& Kay, 2010). Both PsyCap and internal locus of control influence how people perceive their environment and the actions they take to influence their circumstances (Culbertson, Fullagar, \& Mills, 2010; Peacock \& Wong, 1996). Therefore, these resources can influence affect balance which may further prevent psychological distress.

PsyCap resources enable individuals to reframe goals, believe in one's abilities, and maintain positive and realistic expectations. Thus it can influence the appraisal of goal incongruence (match between events and goals) and goal relevance during unexpected events (Moors, 2017). People high in PsyCap may view the lockdown as a temporary event, accept the changed circumstances (Rabenu, Yaniv, \& Elizur, 2016), and maintain positive functioning (Luthans \& YoussefMorgan, 2017). Also, in spite of restrictions, they are likely to keep striving toward goals driven by their ability to find alternate pathways and confidence (Utsey, Giesbrecht, Hook, \& Stanard, 2008). Such positive appraisals and striving may form the basis of experiencing affect balance (Kun \& Gadanecz, 2019; Moors, 2017) and prevent psychological distress. Hence, it is expected that:

H3: Affect balance mediates the relationship between PsyCap and psychological distress.

Internals, as compared to externals, either control their negative mood better or secure positive outcomes and feelings, or both (Gallagher, Bentley, \& Barlow, 2014; Henson \& Chang, 1998; Klonowicz, 2001). This may be because the patterns of appraisal and coping reported by internals are more adaptive (Heinstrom, 2010; Peacock \& Wong, 1996). Even in adverse situations, internals may react to problems more constructively and proactively search for solutions (Gianakos, 2002; Kulshresta \& Sen, 2006; Ng, Sorensen, \& Eby, 2006). For example, at the workplace, people with internal locus of control believe that they themselves control their work roles and such beliefs give rise to positive affective reactions ( $\mathrm{Ng}$ et al., 2006). Furthermore, in Asian population, though responsibility for success and failure is shared with others, when attributions of success are made to oneself it leads to positive affect (Yeo et al., 2017). Therefore, during the lockdown, the belief that efforts can bear positive consequences, may form the basis of affect balance (Avey et al., 2011) and reduce psychological distress. Hence, it is expected that:

H4: Affect balance mediates the relationship between internal locus of control and psychological distress.

Internal locus of control and PsyCap are associated with both the dimensions of mental health, that is, improved wellbeing and reduced psychological distress (Schurer, 2014). However, these are two different control-related resources. While PsyCap represents the belief in one's ability to overcome difficulties and positive outcomes, internal locus of control represents the expectancy that one's actions will bear 
desired consequences (Shapiro Jr., Schwartz, \& Astin, 1996). This research will facilitate an understanding of the associations of these two control-related psychological resources with mental health in a situation where the perceptions of control are severely challenged. There is already considerable research on prevalent mental health problems and risk factors for mental health deterioration during COVID-19 lockdowns (Rajkumar, 2020; Vindegaard \& Benros, 2020). This study will complement such research by contributing to the literature on protective role of psychological resources for mental health during COVID-19 lockdown. The conceptual model is shown in Fig. 1.

\section{Method}

\section{Participants}

Participants included 667 self-selected adults. Based on Soper's (2020) sample size calculator, the minimum sample recommended for structural equation modelling with nine latent variables, 28 observed variables, anticipated effect size of 0.30 , desired probability level of 0.001 , and desired statistical power of 0.90 is 337 . Hence, the sample size of 667 is adequate to achieve statistically satisfactory effect size. Individuals over 18 years of age and residing in a city which reported confirmed cases of COVID-19 were invited to participate in the study. The participants were from 20 states (out of 28 states in India) and two union territories (out of eight union territories in India; union territories are governed directly by the Central Government of India). Participants represented all the geographical regions of the country. People with pre-existing psychiatric conditions and recent visit to any psychiatrist were requested not to respond to the survey. The sample included a balanced mix of 311 males $(46.6 \%)$ and 356 females $(53.4 \%)$. Table 1 shows the sociodemographic profile of the participants.

\section{Measures}

The summed score of multi-item inventories was divided by the number of items to keep the value within the range of the response scale (Song, Lin, Ward, \& Fine, 2013; Uebersax, 2006). The General Health Questionnaire-12 (GHQ-12), a self-report questionnaire, was used to detect psychological distress (Baxter et al., 2014; Goldberg \& Williams, 1988; Montazeri et al., 2003). The scale assesses three dimensions of psychological distress: social dysfunction, anxiety and depression, and loss of confidence (Graetz, 1991). Likert scoring $(0-1-2-3)$ was used in this study. The response descriptions were, $0=$ less than usual, $1=$ no more than usual, $2=$ rather more than usual, and $3=$ much more than usual. High scores indicated psychological distress.

PsyCap was measured using the Compound PsyCap Scale (CPC-12; Lorenz, Beer, Pütz, \& Heinitz, 2016). The CPC-12 is a non-domain specific measure of psychological capital and includes three items for each of the components of hope, efficacy, resilience, and optimism. The response descriptors were on a 6-point scale from 1 (strongly disagree) to 6 (strongly agree).

Internal locus of control was assessed by ten items adapted from Rotter's (1966) internal-external locus of control scale. Eight of the ten items measured locus of control and the remaining two items were filler questions.

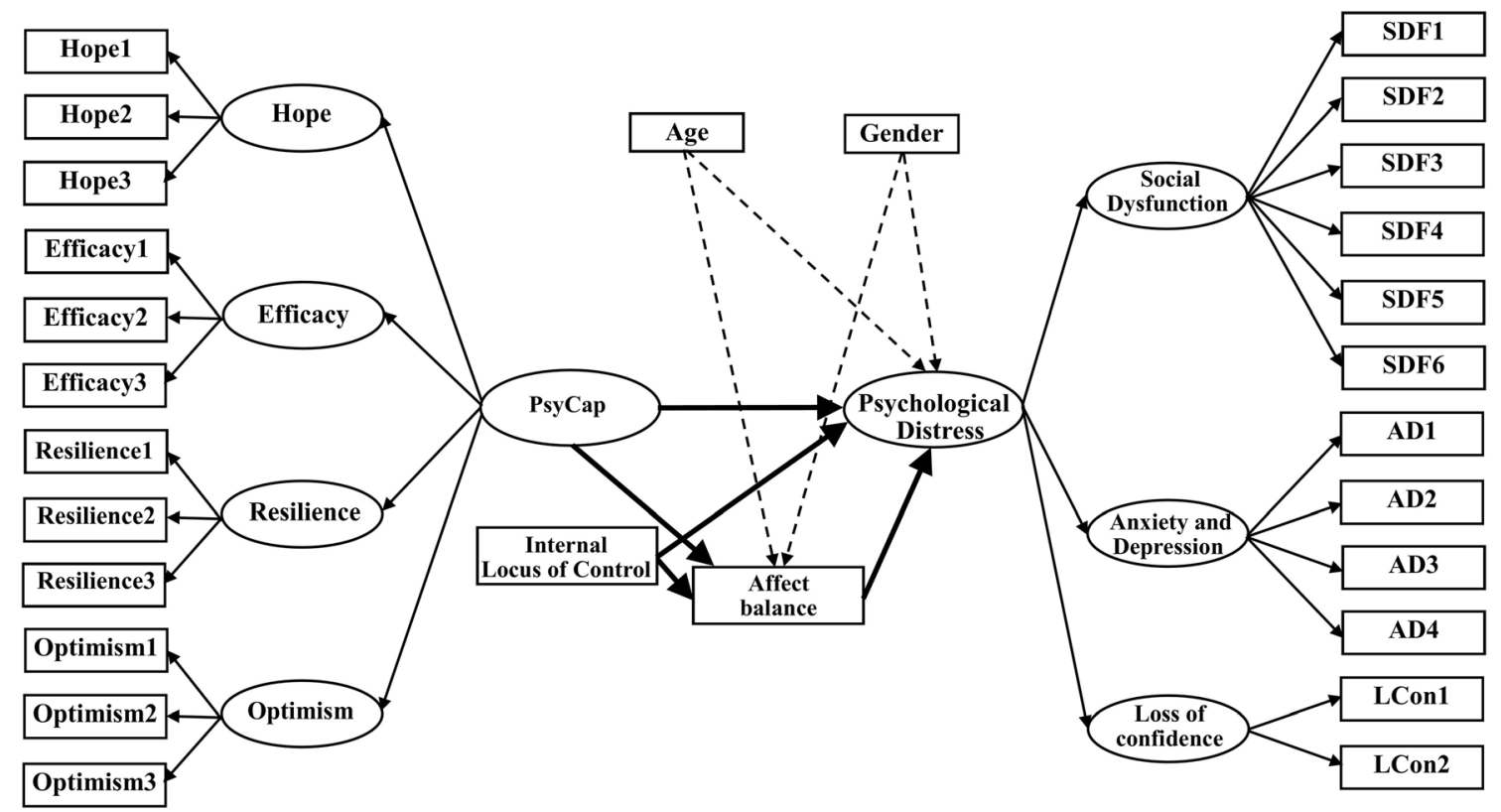

Fig. 1 Conceptual Model 
Table 1 Sociodemographic profile of the participants

\begin{tabular}{|c|c|c|c|c|c|c|}
\hline Characteristics & $\mathrm{N}$ & $\%$ & Mean & SD & Min & Max \\
\hline \multicolumn{7}{|l|}{ Gender } \\
\hline Male & 311 & 46.6 & & & & \\
\hline Female & 356 & 53.4 & & & & \\
\hline Age & & & 30.97 & 11.34 & 18 & 78 \\
\hline \multicolumn{7}{|l|}{ Marital status } \\
\hline Single & 412 & 61.8 & & & & \\
\hline Married & 248 & 37.2 & & & & \\
\hline Divorced & 4 & 0.6 & & & & \\
\hline Separated & 3 & 0.4 & & & & \\
\hline Family size & & & 4 & 1 & 2 & 8 \\
\hline \multicolumn{7}{|l|}{ Religion } \\
\hline Atheism & 28 & 4.2 & & & & \\
\hline Buddhism & 3 & 0.4 & & & & \\
\hline Christianity & 85 & 12.7 & & & & \\
\hline Hinduism & 494 & 74.1 & & & & \\
\hline Islam & 39 & 5.8 & & & & \\
\hline Jainism & 8 & 1.2 & & & & \\
\hline Sikhism & 9 & 1.3 & & & & \\
\hline Taoism & 1 & 0.1 & & & & \\
\hline \multicolumn{7}{|c|}{ Highest qualification } \\
\hline High school & 13 & 1.9 & & & & \\
\hline Intermediate & 43 & 6.4 & & & & \\
\hline Graduate & 187 & 28.0 & & & & \\
\hline Post-graduate & 335 & 50.2 & & & & \\
\hline $\mathrm{PhD}$ & 89 & 13.3 & & & & \\
\hline \multicolumn{7}{|l|}{ Profession } \\
\hline Student & 272 & 40.8 & & & & \\
\hline Unemployed & 21 & 3.1 & & & & \\
\hline Employed & 315 & 47.2 & & & & \\
\hline Self-employed & 48 & 7.2 & & & & \\
\hline Retired & 11 & 1.6 & & & & \\
\hline
\end{tabular}

Each item contained a pair of statements, one indicating external (coded as 0 ) and the other indicating internal (coded as 1) orientation. High scores indicated more internal locus of control.

The Scale of Positive and Negative Experience (SPANE; Diener et al., 2010) assessed positive affect and negative affect. Participants were asked to report how often they experienced six positive and six negative feelings on a 5-point scale ranging from 1 (Very rarely or never) to 5 (Very often or always). Negative feelings score were subtracted from the positive feelings score to compute affect balance (Diener et al., 2010). A high affect balance indicated that a participant rarely or never experienced any of the negative feelings, and very often or always had all of the positive feelings in past four weeks.

\section{Procedure}

Data were collected in the second week of the lockdown during 30 March - 5 April, 2020. An online survey form with an invitation to participate in the survey was shared in the authors' alumni network, student groups, and among personal contacts. An invitation text or mail was shared that included study information, an informed consent form, and a web link to the survey. The survey was in English.

\section{Results}

Confirmatory factor analysis (CFA) and path analysis were carried out using IBM AMOS 24. A hybrid model was tested. PsyCap and internal locus of control were independent variables, affect balance was the mediator variable, and psychological distress was the dependent variable. Gender and age were control variables. PsyCap was a second-order variable with four first-order factors: hope, efficacy, resilience, and optimism. Internal locus of control, affect balance, gender, and age were observed variables. Psychological distress was a second-order variable with three first-order factors: social dysfunction, anxiety and depression, and loss of confidence. Gender and age were modelled as control variables to partial out their effect on affect balance and psychological distress. Gender was a categorical variable $(1=$ male, $2=$ female $)$ and age was a continuous variable. The maximum likelihood method of covariance-based structural equation modeling (SEM) was used to test the hypotheses.

The descriptive statistics and correlations for all variables are shown in Table 2. PsyCap and its first-order factors were positively related with each other and were also positively related with internal locus of control, positive affect, and affect balance but inversely related to negative affect, and psychological distress and its three dimensions. Internal locus of control was positively related with positive affect and affect balance but inversely related with negative affect and psychological distress and its dimensions. Positive affect was positively related with affect balance and inversely related to negative affect and psychological distress and its dimensions. Affect balance was inversely related to psychological distress and all its dimensions. Psychological distress and its three dimensions were positively related with each other. Though correlation supported the hypothesized direct relations, the relations were bidirectional, therefore path analysis was carried out.

Table 3 presents CFA results. All the items and the firstorder factors had significant loadings $(p \leq .001)$ on the respective variables. Each variable had acceptable convergent validity (average variance extracted) $>.50$ and acceptable composite reliability > .70 (Hair Jr, Matthews, Matthews, \& Sarstedt, 2017). CFA models for all the variables had acceptable fit indices. The square roots of the average variance extracted 
Table 2 Descriptive statistics and correlations for all variables

\begin{tabular}{|c|c|c|c|c|c|c|c|c|c|c|c|c|c|}
\hline Variables & 1 & 2 & 3 & 4 & 5 & 6 & 7 & 8 & 9 & 10 & 11 & 12 & 13 \\
\hline \multicolumn{14}{|l|}{ 1. PsyCap } \\
\hline 2. Hope & $.80 * * *$ & .74 & & & & & & & & & & & \\
\hline 3. Efficacy & $.84 * * *$ & $.54 * * *$ & .74 & & & & & & & & & & \\
\hline 4. Resilience & $.81 * * *$ & $.48 * * *$ & $.64 * * *$ & .71 & & & & & & & & & \\
\hline 5. Optimism & $.85 * * *$ & $.57 * * *$ & $.62 * * *$ & $.60 * * *$ & .79 & & & & & & & & \\
\hline 6. ILoC & $.26 * * *$ & $.21 * * *$ & $.22 * * *$ & $.17 * * *$ & $.27 * * *$ & & & & & & & & \\
\hline 7. PA & $.43 * * *$ & $.34 * * *$ & $.41 * * *$ & $.29 * * *$ & $.37 * * *$ & $.26 * * *$ & & & & & & & \\
\hline 8. NA & $-.40 * * *$ & $-.33 * * *$ & $-.34 * * *$ & $-.30 * * *$ & $-.36 * * *$ & $-.28 * * *$ & $-.51 * * *$ & & & & & & \\
\hline 9. $\mathrm{AB}$ & $.48 * * *$ & $.38 * * *$ & $.43 * * *$ & $.34 * * *$ & $.42 * * *$ & $.31 * * *$ & $.86^{* * *}$ & $-.88 * * *$ & & & & & \\
\hline 10. PD & $-.47 * * *$ & $-.37 * * *$ & $-.40 * * *$ & $-.38 * * *$ & $-.40 * * *$ & $-.24 * * *$ & $-.45^{* * *}$ & $.48 * * *$ & $-.55^{* * * *}$ & & & & \\
\hline 11. SDF & $-.47 * * *$ & $-.43 * * *$ & $-.39 * * *$ & $-.36^{* * *}$ & $-.37 * * *$ & $-.12 * *$ & $-.40 * * *$ & $.41 * * *$ & $-.47 * * *$ & $.75 * * *$ & .71 & & \\
\hline 12. $\mathrm{AD}$ & $-.54 * * *$ & $-.43 * * *$ & $-.45 * * *$ & $-.43 * * *$ & $-.47 * * *$ & $-.25 * * *$ & $-.43 * * *$ & $.49 * * *$ & $-.53 * * *$ & $.82 * * *$ & $.70 * * *$ & .77 & \\
\hline 13. LCon & $-.47 * * *$ & $-.40 * * *$ & $-.40 * * *$ & $-.37 * * *$ & $-.39 * * *$ & $-.20 * * *$ & $-.37 * * *$ & $.40 * * *$ & $-.44 * * *$ & $.77 * * *$ & $.69 * * *$ & $.76^{* * * *}$ & .84 \\
\hline M & 4.76 & 4.55 & 4.82 & 4.79 & 4.89 & 3.89 & 3.60 & 2.78 & 0.84 & 1.25 & 1.40 & 0.96 & 0.88 \\
\hline SD & 0.74 & 0.94 & 0.87 & 0.78 & 0.97 & 0.91 & 0.83 & 0.88 & 1.48 & 0.62 & 0.59 & 0.68 & 0.72 \\
\hline
\end{tabular}

Bold-faced values on the diagonal represent the square root of each factor's AVE. ILoC internal locus of control, $P A$ positive affect, $N A$ negative affect, $A B$ affect balance, $P D$ psychological distress, $S D F$ social dysfunction, $A D$ anxiety and depression, $L C o n$ loss of confidence

$* * p<0.01$

$* * * p<0.001$

(bold-faced values in the diagonal of Table 2) are all greater than their respective off-diagonal elements. This establishes the discriminant validity of the first-order factors.

To test the direct effect of PsyCap and internal locus of control on psychological distress, the bootstrap procedure in SEM was utilized. Ten-thousand bootstrap samples with biascorrected $95 \%$ confidence intervals were estimated. As shown in Table 4, gender and age were not related with psychological distress. Both PsyCap and internal locus of control were negatively associated with psychological distress. Hence, $\mathrm{H} 1$ and $\mathrm{H} 2$ were supported.

Similarly, to test the indirect effect of PsyCap on psychological distress via affect balance and the indirect effect of internal locus of control on psychological distress via affect balance, the bootstrap procedure in SEM was utilized. Tenthousand bootstrap samples with bias-corrected $95 \%$
Table 3 Factor loading range, reliability, and validity of studied variables

\begin{tabular}{lllllllll}
\hline Variables/Dimensions & $\lambda^{\mathrm{a}}$ range & $\mathrm{AVE}^{\mathrm{b}}$ & $\alpha^{\mathrm{c}}$ & $\begin{array}{l}\chi^{2 /} \\
\mathrm{df}\end{array}$ & GFI & CFI & TFI & RMSEA \\
\hline PsyCap & & & 0.90 & 2.88 & 0.97 & 0.98 & 0.97 & 0.05 \\
Hope & $(.74-.74)$ & 0.55 & 0.78 & & & & & \\
Efficacy & $(.65-.79)$ & 0.55 & 0.77 & & & & & \\
Resilience & $(.62-.86)$ & 0.51 & 0.73 & & & & & \\
Optimism & $(.76-.83)$ & 0.63 & 0.84 & & & & & \\
Positive affect & $(.71-.90)$ & 0.62 & 0.90 & 5.15 & 0.98 & 0.99 & 0.97 & 0.07 \\
Negative affect & $(.77-.85)$ & 0.67 & 0.92 & 3.67 & 0.99 & 0.99 & 0.99 & 0.06 \\
Psychological distress & & & 0.92 & 3.80 & 0.95 & 0.97 & 0.96 & 0.06 \\
Social dysfunction & $(.66-.73)$ & 0.50 & 0.85 & & & & & \\
Anxiety and depression & $(.68-.91)$ & 0.58 & 0.85 & & & & & \\
Loss of confidence & $(.82-.85)$ & 0.70 & 0.82 & & & & & \\
\hline
\end{tabular}

${ }^{\mathrm{a}}$ standardized factor loading

${ }^{\mathrm{b}}$ Average variance extracted or convergent validity

${ }^{c}$ Cronbach's alpha 
Table 4 Direct effect of PsyCap and internal locus of control on psychological distress

\begin{tabular}{|c|c|c|c|c|c|c|c|}
\hline \multicolumn{2}{|l|}{ Paths } & \multirow{2}{*}{$\frac{\beta}{0.78}$} & \multirow[t]{2}{*}{ S.E. } & \multirow{2}{*}{$\begin{array}{c}L L C I \\
0.69\end{array}$} & \multirow{2}{*}{$\begin{array}{c}U L C I \\
0.86\end{array}$} & \multirow{2}{*}{$\frac{p}{* * *}$} & \multirow[t]{2}{*}{ Decision } \\
\hline & PsyCap $\rightarrow$ Hope & & & & & & \\
\hline & PsyCap $\rightarrow$ Efficacy & 0.91 & 0.09 & 0.85 & 0.96 & $* * *$ & \\
\hline & PsyCap $\rightarrow$ Resilience & 0.88 & 0.07 & 0.83 & 0.93 & $* * *$ & \\
\hline & PsyCap $\rightarrow$ Optimism & 0.85 & 0.09 & 0.79 & 0.91 & $* * *$ & \\
\hline & Psychological distress $\rightarrow$ Social dysfunction & 0.86 & & 0.83 & 0.89 & $* * *$ & \\
\hline & Psychological distress $\rightarrow$ Anxiety and depression & 0.99 & 0.08 & 0.98 & 0.99 & $* * *$ & \\
\hline & Psychological distress $\rightarrow$ Lack of confidence & 0.94 & 0.08 & 0.91 & 0.97 & $* * *$ & \\
\hline & Gender $\rightarrow$ Psychological distress & 0.05 & 0.03 & -0.02 & 0.11 & 0.16 & \\
\hline & Age $\rightarrow$ Psychological distress & -0.04 & 0.00 & -0.10 & 0.02 & 0.25 & \\
\hline $\mathrm{H} 1$ & PsyCap $\rightarrow$ Psychological distress & -0.58 & 0.04 & -0.65 & -0.50 & $* * *$ & Supported \\
\hline $\mathrm{H} 2$ & Internal locus of control $\rightarrow$ Psychological distress & -0.10 & 0.01 & -0.17 & -0.02 & $* *$ & Supported \\
\hline
\end{tabular}

$\beta$ Standardized path coefficient, S.E. Standard error, $L L C I$ lower level confidence interval, ULCI upper level confidence interval.

$\chi 2 / \mathrm{df}=2.41 ; \mathrm{GFI}=.92 ; \mathrm{CFI}=.94 ; \mathrm{TLI}=.94 ; \mathrm{RMSEA}=.05$.

$* * p<0.01$

$* * * p<0.001$

confidence intervals were estimated. As shown in Table 5, gender was not related with any of the variables whereas age was significantly related with affect balance $(\beta=0.14$, $p=.001)$, but not with psychological distress. As hypothesized, the indirect effects of PsyCap $(\beta=-.15, p<.001)$ and internal locus of control $(\beta=-0.06, p<.001)$ on psychological distress via affect balance respectively were significant. The size of the indirect effect of a predictor variable on a criterion variable via a mediator variable gives a clear picture of the strength of the mediation (Hayes, 2009). The effect size is small at .01, medium at .09, and large at .25 (Kenny, 2018). The indirect effect of PsyCap $(\beta=-.15)$ on

Table 5 Indirect effect of PsyCap and internal locus of control on psychological distress

\begin{tabular}{|c|c|c|c|c|c|c|c|}
\hline \multicolumn{2}{|l|}{ Paths } & \multirow{2}{*}{$\frac{\beta}{0.78}$} & \multirow[t]{2}{*}{ S.E. } & \multirow{2}{*}{$\frac{L L C I}{0.68}$} & \multirow{2}{*}{$\begin{array}{c}U L C I \\
0.85\end{array}$} & \multirow{2}{*}{$\frac{p}{* * *}$} & \multirow[t]{2}{*}{ Decision } \\
\hline & PsyCap $\rightarrow$ Hope & & & & & & \\
\hline & PsyCap $\rightarrow$ Efficacy & 0.91 & 0.09 & 0.86 & 0.96 & $* * *$ & \\
\hline & PsyCap $\rightarrow$ Resilience & 0.88 & 0.07 & 0.82 & 0.93 & $* * *$ & \\
\hline & PsyCap $\rightarrow$ Optimism & 0.85 & 0.09 & 0.79 & 0.91 & $* * *$ & \\
\hline & Psychological distress $\rightarrow$ Social dysfunction & 0.86 & & 0.83 & 0.90 & $* * *$ & \\
\hline & Psychological distress $\rightarrow$ Anxiety and depression & 0.99 & 0.08 & 0.98 & 0.99 & $* * *$ & \\
\hline & Psychological distress $\rightarrow$ Lack of confidence & 0.94 & 0.08 & 0.90 & 0.97 & $* * *$ & \\
\hline & Gender $\rightarrow$ Affect balance & -0.05 & 0.10 & -0.12 & 0.01 & 0.14 & \\
\hline & Gender $\rightarrow$ Psychological distress & 0.03 & 0.03 & -0.03 & 0.09 & 0.32 & \\
\hline & Age $\rightarrow$ Affect balance & 0.14 & 0.00 & 0.07 & 0.21 & $* * *$ & \\
\hline & Age $\rightarrow$ Psychological distress & 0.00 & 0.00 & -0.06 & 0.06 & 0.90 & \\
\hline & PsyCap $\rightarrow$ Affect balance & 0.46 & 0.11 & 0.37 & 0.52 & $* * *$ & \\
\hline & Internal locus of control $\rightarrow$ Affect balance & 0.19 & 0.02 & 0.11 & 0.27 & $* * *$ & \\
\hline & Affect balance $\rightarrow$ Psychological distress & -0.32 & 0.01 & -0.39 & -0.24 & $* * *$ & \\
\hline $\mathrm{H} 3$ & PsyCap $\rightarrow$ Affect balance $\rightarrow$ Psychological distress & -0.15 & 0.02 & -0.19 & -0.11 & $* * *$ & Supported \\
\hline $\mathrm{H} 4$ & Internal locus of control $\rightarrow$ Affect balance $\rightarrow$ Psychological distress & -0.06 & 0.02 & -0.09 & -0.03 & $* * *$ & Supported \\
\hline
\end{tabular}

$\beta$ Standardized path coefficient, S.E. Standard error, $L L C I$ lower level confidence interval, ULCI upper level confidence interval $\chi 2 / \mathrm{df}=2.37 ; \mathrm{GFI}=.92 ; \mathrm{CFI}=.95 ; \mathrm{TLI}=.94 ; \mathrm{RMSEA}=.05$.

$* * * p<0.001$ 
psychological distress was medium and that of internal locus of control $(\beta=-.06)$ was low. Among the various components of PsyCap, efficacy was the most important component followed by resilience and optimism. Among the three dimensions of psychological distress, anxiety and depression was the most important dimension followed by lack of confidence and social dysfunction.

\section{Discussion}

This research examined the relationships of PsyCap and internal locus of control with psychological distress and the role of affect balance as a mediator in these two relationships. People high in PsyCap and internal locus of control reported low levels of psychological distress. Out of the two independent variables, PsyCap had stronger negative association with psychological distress than internal locus of control. Affect balance mediated the relationships between PsyCap and psychological distress, and that of internal locus of control and psychological distress. However, PsyCap had a stronger indirect effect on psychological distress through affect balance than internal locus of control.

Recent studies emphasize the role of PsyCap in preventing psychological distress during COVID-19 (Dimino, Horan, \& Stephenson, 2020; Kim, 2020). Findings of this study provide empirical evidence that people high in PsyCap experienced low psychological distress during the early phases of lockdown in India. PsyCap fosters positive outcomes not only in organizations but also in multiple life domains such as interpersonal relationships (Avey, Wernsing, \& Luthans, 2008) and academic performance (Finch et al., 2020). Thus, PsyCap can be valuable in managing distress during lockdown as all spheres of life have been affected and personal and professional lives have overlapped (Wallace \& Patrick, 2020). Just as PsyCap prevents burnout (Moyer, Aziz, \& Wuensch, 2017) and facilitates positive attitudes toward organizational change (Avey et al., 2008), it may enable individuals to overcome distress associated with changed work-life settings during the lockdown.

The negative association of internal locus of control with psychological distress supports existing evidence (Papanikolaou et al., 2013); however the association is moderate. This may be because the strength of relationship between internal control and psychological distress depends on the nature of the stressor during periods of prolonged uncertainty. The negative associations are stronger for stressors perceived to be controllable than for those perceived to be uncontrollable (Papanikolaou et al., 2013; Peacock \& Wong, 1996). Furthermore, when stressors are not completely controllable, a mix of external and internal locus of control may be more useful (April, Dharani, \& Peters, 2012). Such evidence suggests that as the stressors experienced during the lockdown are not fully controllable, internal locus of control is only moderately effective in arresting mental health deterioration. The lockdown was initially declared for a limited time of 21 days, and there were some areas of personal control such as taking care of personal hygiene. Therefore, internals might have perceived some opportunities for control which arrested psychological distress to some extent.

Consistent with previous findings (Avey et al., 2008; Burns, Anstey, \& Windsor, 2011), the mediation analyses revealed that PsyCap associates with affect balance which further protects against psychological distress. Such results provide evidence that in addition to the workplace, PsyCap can be a source of affect balance during stressful events in day-to-day lives too (Avey et al., 2008). Earlier studies have found strong direct associations of PsyCap with well-being, in spite of the presence of intervening variables like coping (Rabenu et al., 2016). PsyCap resources enables greater emotional complexity and emotional control which enables people to mobilize positive emotions during stressful periods (Avey et al., 2008; Luthans et al., 2007; Tugade, Fredrickson, \& Feldman Barrett, 2004). Thus, people high in PsyCap may be prone to experience more positive affect (Diener \& Fujita, 1995; Kun \& Gadanecz, 2019). Affect balance, further enables realizing the positive expectations by prompting approach and exploration behaviors (Fredrickson \& Losada, 2005) which may reduce distress.

The relation of internal locus of control with psychological distress was also partially mediated by affect balance. Therefore, internals' belief that their efforts can help manage the lockdown is associated with positive affect and may have protected them from distress. Earlier evidence suggests that perceptions of control is associated with affect (Taylor et al., 1991). Individuals with internal control can overcome negative feelings and experience less mood swings which facilitates better adaptation to adverse situations (Schurer 2014). Studies have shown that in spite of adversities, internals continue to be efficient due to their healthy habits and willingness to overcome problems (Schurer 2014). Thus individuals high in PsyCap and internal locus of control, may experience more success episodes and thus positive life events even amidst the lockdown, and may thus experience less distress. However, the partial mediation of affect balance suggests the presence of some other mechanisms.

These findings provide evidence of the role of affect balance in carrying forward the effects of psychological resources to reduce distress. Affect balance denotes an individual's reactions to current events (Diener \& Lucas, 1999). Therefore, the mediation results show that PsyCap and internal locus of control are associated with affective reactions of people to the lockdown which further affects mental health problems. Control related psychological resources may sustain good mental health (Seligman, Steen, Park, \& Peterson, 2005) and different resources can be salient for well-being in 
different life circumstances (Diener \& Fujita, 1995). The findings provide evidence that PsyCap and internal locus of control are associated with affect balance during uncertain life circumstances and thereby are valuable resources for adjusting to pandemic mitigation measures.

The comparison of the direct and indirect associations of PsyCap and internal locus of control with psychological distress shows how different types of control beliefs may have different association with overall mental health during the lockdown. Though both the resources negatively predicted psychological distress, PsyCap had stronger direct and indirect effects on psychological distress than internal locus of control. This can be because people with more resources are expected to experience more well-being (Hobfoll, 2011). PsyCap as a resource caravan enables individuals to draw from multiple resources and can have stronger influence on psychological outcomes than individual resources such as internal locus of control. Furthermore, PsyCap provides the belief in one's abilities to overcome adversities while internal control provides the belief that one is responsible for one's life outcomes (Wallston, 2015). In a situation such as a sudden lockdown the scope of control over consequences is limited. This might explain the weaker direct and indirect associations of internal locus of control with psychological distress via affect balance as compared to PsyCap. Therefore, the belief in one's abilities to steer ahead in spite of difficulties may be more predictive of well-being and psychological distress, than feeling responsible but not finding enough opportunities to exert control.

\section{Implications}

The findings add to the theoretical literature on controlrelated resources and provide evidence of the relevance of PsyCap and internal locus of control for overall mental health during pandemic. The findings also lend empirical support to the ongoing discourse on the benefits of positivity in managing mental health during the COVID-19 outbreak (Hagger et al., 2020; WHO, 2020). The Ministry of Health and Family Welfare (Government of India, 2020) has indicated the role of perceptions of control and positive emotions in managing mental health during the lockdown. This study provides evidence that during COVID-19, interventions to build psychological resources may prevent the loss of well-being and thereby prevent psychological distress. As PsyCap emerges as a stronger protective measure against psychological distress than internal locus of control, interventions should aim to make individuals feel efficacious and build their ability to look for alternate pathways to reach their goals in their day-to-day lives. Interventions can help more internally oriented individuals to identify the aspects of their lives they might be able to control. These findings have implications for psychotherapy interventions such as cognitive behavioral therapy, mindfulness-based cognitive therapy, and psychoeducation which have been employed to develop adaptive attributes during COVID-19 (Ho, Chee, \& Ho, 2020).

\section{Limitations and Future Directions}

The study has few limitations. First, the cross-sectional design of the study does not allow causal relations to be examined. Second, the use of convenience sampling and self-selected participants limits the generalization of the findings. Third, the sample consisted of the Indian citizens only, hence findings cannot be generalized to people in other countries with differing levels of COVID-19 severity. Fourth, the indirect effects in the study are moderate in size which indicates the possible presence of other mediators. Therefore, other mediators such as coping styles can be examined in future researches to understand the mechanisms through which PsyCap and locus of control reduce psychological distress. Future researchers can test this model adopting a longitudinal design which allows the assessment of mental health outcomes at different phases of the lockdown and can also make cross country comparison. This will provide more robust evidence on the role of PsyCap and internal locus of control in protecting against psychological distress.

\section{Conclusion}

COVID-19 has restricted the way we would love to live our life, which challenges hope every day, making psychological distress related consequences inevitable. Understanding the sources of positive mental health can help in understanding 'what' and 'how' to work upon, to mitigate the mental health decline of the society during the pandemic. To this end, to the best of our knowledge, this study is one of the earliest studies to present empirical evidence of the role of different types of control resources, PsyCap and internal locus of control in managing mental health during a COVID-19 lockdown. The final solution to COVID-19 pandemic is out of sight. Policy making for COVID-19 mental health may focus on interventions to build psychological resources of individuals and help assess areas where exercising control is possible.

Data Availability Data will be made available upon request.

\section{Declarations}

Conflict of Interest Authors do not have any conflict of interest. 


\section{References}

Ajmal, A. (2020). Citizens, NGOs reach out to the needy with food, rations \& cash. The times of India. Retrieved April 5, 2020, from https://timesofindia.indiatimes.com/india/citizens-ngos-reach-outto-the-needy-with-food-rations-cash/articleshow/74855828.cms.

April, K. A., Dharani, B., \& Peters, K. (2012). Impact of locus of control expectancy on level of well-being. Review of European Studies, 4(2), 124-137. https://doi.org/10.5539/res.v4n2p124.

Arora, A., Jha, A. K., Alat, P., \& Das, S. S. (2020). Understanding coronaphobia. Asian Journal of Psychiatry, 102384, 102384. https://doi.org/10.1016/j.ajp.2020.102384.

Avey, J. B., Wernsing, T. S., \& Mhatre, K. H. (2011). A longitudinal analysis of positive psychological constructs and emotions on stress, anxiety, and well-being. Journal of Leadership and Organizational Studies, 18(2), 216-228. https://doi.org/10.1177/ 1548051810397368

Avey, J. B., Wernsing, T. S., \& Luthans, F. (2008). Can positive employees help positive organizational change? Impact of psychological capital and emotions on relevant attitudes and behaviors. Journal of Applied Behavioral Science, 44(1), 48-70. https://doi. org/10.1177/0021886307311470.

Baxter, A. J., Scott, K. M., Ferrari, A. J., Norman, R. E., Vos, T., \& Whiteford, H. A. (2014). Challenging the myth of an "epidemic" of common mental disorders: Trends in the global prevalence of anxiety and depression between 1990 and 2010. Depression and Anxiety, 31(6), 506-516. https://doi.org/10.1002/da.22230.

Burns, R. A., Anstey, K. J., \& Windsor, T. D. (2011). Subjective wellbeing mediates the effects of resilience and mastery on depression and anxiety in a large community sample of young and middle-aged adults. Australian and New Zealand Journal of Psychiatry, 45(3), 240-248. https://doi.org/10.3109/00048674.2010.529604.

Carmona-Halty, M., Salanova, M., Llorens, S., \& Schaufeli, W. B. (2019). Linking positive emotions and academic performance: The mediated role of academic psychological capital and academic engagement. Current Psychology. https://doi.org/10.1007/s12144019-00227-8

Centers for Disease Control and Prevention (2020). Stress and coping. Retrieved May 1, 2020, from https:/www.cdc.gov/coronavirus/ 2019-ncov/daily-life-coping/managing-stress-anxiety.html.

Chakraborty, N. (2020). The COVID-19 pandemic and its impact on mental health. Progress in Neurology and Psychiatry, 24(3), 20 25. https://doi.org/10.1002/pnp.666.

Culbertson, S. S., Fullagar, C. J., \& Mills, M. J. (2010). Feeling good and doing great: The relationship between psychological capital and well-being. Journal of Occupational Health Psychology, 15(4), 421-433. https://doi.org/10.1037/a0020720.

Diehl, M., \& Berg, K. M. (2011). The ratio between positive and negative affect and flourishing mental health across adulthood. Aging and Mental Health, 15(7), 882-893. https://doi.org/10.1080/13607863. 2011.569488

Diener, E., \& Fujita, F. (1995). Resources, personal strivings, and subjective well-being: A nomothetic and idiographic approach. Journal of Personality and Social Psychology, 68(5), 926-935. https://doi. org/10.1037/0022-3514.68.5.926.

Diener, E., \& Lucas, R. E. (1999). Personality and subjective well-being. In D. Kahneman, E. Diener, \& N. Schwarz (Eds.), Well-being: The foundations of hedonic psychology. Verona: Russell Sage.

Diener, E., Wirtz, D., Tov, W., Kim-Prieto, C., Choi, D. W., Oishi, S., \& Biswas-Diener, R. (2010). New well-being measures: Short scales to assess flourishing and positive and negative feelings. Social Indicators Research, 97(2), 143-156. https://doi.org/10.1007/ s11205-009-9493-y.

Dimino, K., Horan, K. M., \& Stephenson, C. (2020). Leading our frontline HEROES through times of crisis with a sense of hope, efficacy, resilience, and optimism. Nurse Leader, 18, 592-596. https://doi. org/10.1016/j.mnl.2020.05.011

Fang, S. E., Prayag, G., Ozanne, L. K., \& de Vries, H. (2020). Psychological capital, coping mechanisms and organizational resilience: Insights from the 2016 Kaikoura earthquake, New Zealand. Tourism Management Perspectives, 34, 100637. https://doi.org/10. 1016/j.tmp.2020.100637.

Finch, J., Farrell, L. J., \& Waters, A. M. (2020). Searching for the HERO in youth: Does psychological capital (PsyCap) predict mental health symptoms and subjective wellbeing in Australian school-aged children and adolescents? Child Psychiatry \& Human Development., 51, 1025-1036. https://doi.org/10.1007/s10578-020-01023-3.

Folkman, S., \& Moskowitz, J. T. (2000). Positive affect and the other side of coping. American Psychologist, 55(6), 647-654. https://doi.org/ 10.1037/0003-066x.55.6.647.

Fredrickson, B. L., \& Losada, M. F. (2005). Positive affect and the complex dynamics of human flourishing. American Psychologist, 60(7), 678-686. https://doi.org/10.1037/0003-066X.60.7.678.

Gallagher, M. W., Bentley, K. H., \& Barlow, D. H. (2014). Perceived control and vulnerability to anxiety disorders: A meta-analytic review. Cognitive Therapy and Research, 38(6), 571-584. https://doi. org/10.1007/s10608-014-9624-x.

Gianakos, I. (2002). Predictors of coping with work stress: The influences of sex, gender role, social desirability, and locus of control. Sex Roles, 46(5-6), 149-158. https://doi.org/10.1023/A: 1019675218338

Goldberg, D. P., \& Williams, P. (1988). Users' guide to the general health questionnaire. Windsor: NFER-Nelson.

Government of India (2020). Minding our minds during the COVID-19. Ministry of Health and Family Welfare. Retrieved May 2, 2020, from ht tps://w w w moh fw.gov.in/pdf/ MindingourmindsduringCoronaeditedat.pdf.

Graetz, B. (1991). Multidimensional properties of the general health questionnaire. Social Psychiatry and Psychiatric Epidemiology, 26(3), 132-138. https://doi.org/10.1007/bf00782952.

Hagger, M. S., Keech, J. J., \& Hamilton, K. (2020). Managing stress during the coronavirus disease 2019 pandemic and beyond: Reappraisal and mindset approaches. Stress and Health, 36(3), 396-401. https://doi.org/10.1002/smi.2969.

Hair Jr., J. F., Matthews, L. M., Matthews, R. L., \& Sarstedt, M. (2017). PLS-SEM or CB-SEM: Updated guidelines on which method to use. International Journal of Multivariate Data Analysis, 1(2), 107-123. https://doi.org/10.1504/IJMDA.2017.087624.

Hayes, A. F. (2009). Beyond Baron and Kenny: Statistical mediation analysis in the new millennium. Communication Monographs, 76(4), 408-442. https://doi.org/10.1080/03637750903310360.

Heinstrom, J. (2010). From fear to flow: Personality and information interaction. Amsterdam: Elsevier.

Henson, H. N., \& Chang, E. C. (1998). Locus of control and the fundamental dimensions of moods. Psychological Reports, 82(3), 13351338. https://doi.org/10.2466/pr0.82.3.1335-1338.

Ho, C. S., Chee, C. Y., \& Ho, R. C. (2020). Mental health strategies to combat the psychological impact of COVID-19 beyond paranoia and panic. Annals Academy of Medicine Singapore, 49(3), 155160. https://doi.org/10.47102/ANNALS-ACADMEDSG.202043.

Hobfoll, S. E. (2002). Social and psychological resources and adaptation. Review of General Psychology, 6(4), 307-324. https://doi.org/10. 1037/1089-2680.6.4.307.

Hobfoll, S. E. (2011). Conservation of resources theory: Its implication for stress, health, and resilience. In S. Folkman (Ed.), The Oxford handbook of stress, health, and coping (pp. 127-147). Oxford: Oxford University Press.

Kenny, D. A. (2018). Mediation. Retrieved April 8, 2020, from http:// www.davidakenny.net $/ \mathrm{cm} /$ mediate.htm.

Keyes, C. L., Dhingra, S. S., \& Simoes, E. J. (2010). Change in level of positive mental health as a predictor of future risk of mental illness. 
American Journal of Public Health, 100(12), 2366-2371. https:// doi.org/10.2105/ajph.2010.192245.

Kim, S. Y. (2020). A convergence study of stress caused by the epidemic of COVID-19, quality of life and positive psychological capital. Journal of the Korea Convergence Society, 11(6), 423-431. https://doi.org/10.15207/JKCS.2020.11.6.423.

Klonowicz, T. (2001). Discontented people: Reactivity and locus of control as determinants of subjective well-being. European Journal of Personality, 15(1), 29-47. https://doi.org/10.1002/per.387.

Krasikova, D. V., Lester, P. B., \& Harms, P. D. (2015). Effects of psychological capital on mental health and substance abuse. Journal of Leadership and Organizational Studies, 22(3), 280-291. https://doi. org/10.1177/1548051815585853.

Kulshresta, U., \& Sen, C. (2006). Subjective well-being in relation to emotional intelligence and locus of control among executives. Journal of the Indian Academy of Applied Psychology, 32(2), 93$98 \mathrm{http} / / /$ medind.nic.in/jak/t06/i1/jakt06i1p93.pdf.

Kun, A., \& Gadanecz, P. (2019). Workplace happiness, well-being and their relationship with psychological capital: A study of Hungarian teachers. Current Psychology. https://doi.org/10.1007/s12144-01900550-0.

Lazarus, R. S. (1991). Emotion and adaptation. Oxford University Press.

Le, X. T. T., Dang, A. K., Toweh, J., Nguyen, Q. N., Le, H. T., Do, T. T. T., ... Ho, R. C. M. (2020). Evaluating the psychological impacts related to COVID-19 of Vietnamese people under the first nationwide partial lockdown in Vietnam. Frontiers in Psychiatry, 11. https://doi.org/10.3389/fpsyt.2020.00824.

Locker, M., \& Hoffman, A. (2020). People quarantined in Italy join together in song from balconies during Coronavirus lockdown. Retrieved April 9, 2020, from https://time.com/5802700/ lockdown-song/.

Lorenz, T., Beer, C., Pütz, J., \& Heinitz, K. (2016). Measuring psychological capital: Construction and validation of the compound PsyCap scale (CPC-12). PLoS One, 11(4), 1-17. https://doi.org/ 10.1371/journal.pone.0152892.

Luthans, F., Youssef, C. M., \& Avolio, B. J. (2007). Psychological capital: Developing the human competitive edge. Oxford University Press.

Luthans, F., \& Youssef-Morgan, C. M. (2017). Psychological capital: An evidence-based positive approach. Annual Review of Organizational Psychology and Organizational Behavior, 4, 339366. https://doi.org/10.1146/annurev-orgpsych-032516-113324.

Machado, L., de Oliveira, I. R., Peregrino, A., \& Cantilino, A. (2019). Common mental disorders and subjective well-being: Emotional training among medical students based on positive psychology. PLoS One, 14(2), e0211926. https://doi.org/10.1371/journal.pone. 0211926

Madhav, N., Oppenheim, B., Gallivan, M., Mulembakani, P., Rubin, E., \& Wolfe, N. (2017). Pandemics: Risks, impacts, and mitigation. In Disease Control Priorities: Improving Health and Reducing Poverty. 3rd edition. The International Bank for Reconstruction and Development/the World Bank.

Manuti, A. (2014). Organizational resilience and individual employability: Psychological capital and change management. In A. Manuti \& P. D. De Palma (Eds.), Why human capital is important for organizations: People come First (pp. 33-49). Palgrave Macmillan.

McClure, J., Walkey, F., \& Allen, M. (1999). When earthquake damage is seen as preventable: Attributions, locus of control and attitudes to risk. Applied Psychology, 48(2), 239-256. https://doi.org/10.1111/j. 1464-0597.1999.tb00060.x.

Montazeri, A., Harirchi, A. M., Shariati, M., Garmaroudi, G., Ebadi, M., \& Fateh, A. (2003). The 12-item general health questionnaire (GHQ-12): Translation and validation study of the Iranian version. Health and Quality of Life Outcomes, 1(1), 66. https://doi.org/10. 1186/1477-7525-1-66.
Moors, A. (2017). Appraisal theory of emotion. In V. Zeigler-Hill \& T. Shackelford (Eds.), Encyclopedia of personality and individual differences. Springer. https://doi.org/10.1007/978-3-319-28099-8 493-1.

Moyer, F., Aziz, S., \& Wuensch, K. (2017). From workaholism to burnout: Psychological capital as a mediator. International Journal of Workplace Health Management, 10(3), 213-227. https://doi.org/10. 1108/ijwhm-10-2016-0074.

Mukherjee, W., Bailay, R., \& Shraivastava, A. (2020). Consumer goods fly off the shelves as coronavirus spreads in India. Retrieved May 2, 2020, from https://economictimes.indiatimes.com/industry/consproducts/fmcg/consumer-goods-fly-off-the $\% 20$ shelves-ascoronavirus-spreads-inindia/articleshow/74644159.cms?utm\% 20 source $=$ contentofinterest\&utm_medium $=$ text\&utm_campaign $=$ cppst.

Ng, T. W., Sorensen, K. L., \& Eby, L. T. (2006). Locus of control at work: A meta-analysis. Journal of Organizational Behavior: The International Journal of Industrial, Occupational and Organizational Psychology and Behavior, 27(8), 1057-1087. https://doi.org/10.1002/job.416.

Niven, K. (2013). Affect. In M. D. Gellman \& J. R. Turner (Eds.), Encyclopedia of behavioral medicine. Berlin: Springer.

Odriozola-González, P., Planchuelo-Gómez, Á., Irurtia, M. J., \& de LuisGarcía, R. (2020). Psychological effects of the COVID-19 outbreak and lockdown among students and workers of a Spanish university. Psychiatry Research, 290, 113108. https://doi.org/10.1016/j. psychres.2020.113108.

Okabe-Miyamoto, K., Folk, D. P., Lyubomirsky, S., \& Dunn, E. W. (2020). Changes in social connection during COVID-19 social distancing: It's not (household) size that matters, it's who you're with. PLoS One, 16(1), e0245009. https://doi.org/10.1371/journal.pone. 0245009.

Pan American Health Organization (2009). Protecting mental health during epidemics. Retrieved April, 22, 2020, from https://www.paho. org/en/documents/protecting-mental-health-during-epidemics

Pandey, D., Bansal, S., Goyal, S., Garg, A., Sethi, N., Pothiyill, D. I., Sreelakshmi, E. S., Sayyad, M. G., \& Sethi, R. (2020). Psychological impact of mass quarantine on population during pandemics: The COVID-19 lock-down (COLD) study. PLoS One, 15(10), e0240501. https://doi.org/10.1371/journal.pone.0240501.

Papanikolaou, V., Gadallah, M., Leon, G. R., Massou, E., Prodromitis, G., Skembris, A., \& Levett, J. (2013). Relationship of locus of control, psychological distress, and trauma exposure in groups impacted by intense political conflict in Egypt. Prehospital and Disaster Medicine, 28(5), 423-427. https://doi.org/10.1017/ S1049023X13008601.

Peacock, E. J., \& Wong, P. T. P. (1996). Anticipatory stress: The relation of locus of control, optimism, and control appraisals to coping. Journal of Research in Personality, 30(2), 204-222. https://doi. org/10.1006/jrpe.1996.0014.

Pfefferbaum, B., \& North, C. S. (2020). Mental health and the Covid-19 pandemic. New England Journal of Medicine, 383(6), 510-512. https://doi.org/10.1056/NEJMp2008017.

Pierce, M., Hope, H., Ford, T., Hatch, S., Hotopf, M., John, A., Kontopantelis, E., Webb, R., Wessely, S., McManus, S., \& Abel, K. M. (2020). Mental health before and during the COVID-19 pandemic: A longitudinal probability sample survey of the UK population. The Lancet Psychiatry, 7(10), 883-892. https://doi.org/10. 1016/s2215-0366(20)30308-4.

Rabenu, E., Yaniv, E., \& Elizur, D. (2016). The relationship between psychological capital, coping with stress, well-being, and performance. Current Psychology, 36(4), 875-887. https://doi.org/10. 1007/s12144-016-9477-4.

Rajkumar, R. P. (2020). COVID-19 and mental health: A review of the existing literature. Asian Journal of Psychiatry, 52, 102066. https:// doi.org/10.1016/j.ajp.2020.102066. 
Rotter, J. B. (1966). Generalized expectancies for internal versus external control of reinforcement. Psychological Monographs General and Applied, 80(1), 1-28. https://doi.org/10.1037/h0092976.

Roy, A., Singh, A. K., Mishra, S., Chinnadurai, A., Mitra, A., \& Bakshi, O. (2020). Mental health implications of COVID-19 pandemic and its response in India. International Journal of Social Psychiatry, 002076402095076. https://doi.org/10.1177/0020764020950769.

Schaubroeck, J. M., Riolli, L. T., Peng, A. C., \& Spain, E. S. (2011). Resilience to traumatic exposure among soldiers deployed in combat. Journal of Occupational Health Psychology, 16(1), 18-37. https://doi.org/10.1037/a0021006.

Schurer, S. (2014). Bouncing back from health shocks: Locus of control, labor supply, and mortality. IZA Discussion Paper No. 8203. Retrieved on December 10, 2020, from http://ftp.iza.org/dp8203. pdf.

Seligman, M. E. P., Steen, T. A., Park, N., \& Peterson, C. (2005). Positive psychology progress: Empirical validation of interventions. American Psychologist, 60(5), 410-421. https://doi.org/10.1037/ 0003-066x.60.5.410.

Shacham, M., Hamama-Raz, Y., Kolerman, R., Mijiritsky, O., Ben-Ezra, M., \& Mijiritsky, E. (2020). COVID-19 factors and psychological factors associated with elevated psychological distress among dentists and dental hygienists in Israel. International Journal of Environmental Research and Public Health, 17(8), 2900. https:// doi.org/10.3390/ijerph17082900.

Shapiro Jr., D. H., Schwartz, C. E., \& Astin, J. A. (1996). Controlling ourselves, controlling our world: Psychology's role in understanding positive and negative consequences of seeking and gaining control. American Psychologist, 51(12), 1213-1230. https://doi.org/10. 1037/0003-066X.51.12.1213.

Smith, B. W., Tooley, E. M., Christopher, P. J., \& Kay, V. S. (2010). Resilience as the ability to bounce back from stress: A neglected personal resource? The Journal of Positive Psychology, 5(3), 166176. https://doi.org/10.1080/17439760.2010.482186.

Song, M., Lin, F., Ward, S. E., \& Fine, J. P. (2013). Composite variables: When and how. Nursing Research, 62(1), 45-49. https://doi.org/10. 1097/nnr.0b013e3182741948.

Soper, D. S. (2020). A-priori sample size calculator for structural equation models [Software]. Available at: http://www.danielsoper.com/ statcalc. Accesssed 01 Dec 2020.

Taylor, S. E., Helgeson, V. S., Reed, G. M., \& Skokan, L. A. (1991). Selfgenerated feeling of control and adjustment to physical illness. Journal of Social Issues, 47(4), 91-109. https://doi.org/10.1111/j. 1540-4560.1991.tb01836.x.

Tee, M. L., Tee, C. A., Anlacan, J. P., Aligam, K. J. G., Reyes, P. W. C., Kuruchittham, V., \& Ho, R. C. (2020). Psychological impact of COVID-19 pandemic in the Philippines. Journal of Affective Disorders, 277, 379-391. https://doi.org/10.1016/J.JAD.2020.08. 043.

The Indian Express (2020). What is the Janata Curfew announced by PM Modi? Retrieved May 2, 2020, from https://indianexpress.com/ article/explained/what-is-janata-curfew-6322545/.

Tran, B. X., Nguyen, H. T., Le, H. T., Latkin, C. A., Pham, H. Q., Vu, L. G., ... Ho, R. C. M. (2020). Impact of COVID-19 on economic well-being and quality of life of the Vietnamese during the national social distancing. Frontiers in Psychology, 11. https://doi.org/10. 3389/fpsyg.2020.565153.

Trompetter, H. R., de Kleine, E., \& Bohlmeijer, E. T. (2017). Why does positive mental health buffer against psychopathology? An exploratory study on self-compassion as a resilience mechanism and adaptive emotion regulation strategy. Cognitive Therapy and Research, 41(3), 459-468. https://doi.org/10.1007/s10608-016-9774-0.

Tugade, M. M., Fredrickson, B. L., \& Feldman Barrett, L. (2004). Psychological resilience and positive emotional granularity: Examining the benefits of positive emotions on coping and health.
Journal of Personality, 72(6), 1161-1190. https://doi.org/10.1111/j. 1467-6494.2004.00294.x.

Uebersax, J. S. (2006). Likert scales: Dispelling the confusion. Statistical methods for rater agreement website. Available at: http://johnuebersax.com/stat/likert.htm. Accessed 29 Sept 2020.

Utsey, S. O., Giesbrecht, N., Hook, J., \& Stanard, P. M. (2008). Cultural, sociofamilial, and psychological resources that inhibit psychological distress in African Americans exposed to stressful life events and race-related stress. Journal of Counseling Psychology, 55(1), 49-62. https://doi.org/10.1037/0022-0167.55.1.49.

Vibha, Prabhu, A. N., Kamath, G. B., \& Pai, D. V. (2020). Keeping the country positive during the COVID 19 pandemic: Evidence from India. Asian Journal of Psychiatry, 51, 102118. https://doi.org/10. 1016/j.ajp.2020.102118.

Vieira, C. M., Franco, O. H., Restrepo, C. G., \& Abel, T. (2020). COVID19: The forgotten priorities of the pandemic. Maturitas, 36, 38-41. https://doi.org/10.1016/j.maturitas.2020.04.004.

Vindegaard, N., \& Benros, M. E. (2020). COVID-19 pandemic and mental health consequences: Systematic review of the current evidence. Brain, Behavior, and Immunity, 89, 531-542. https://doi.org/10. 1016/j.bbi.2020.05.048.

Wallace, J., \& Patrick, V. (2020). Life in lockdown is testing parents' bandwidth, but there are ways to protect your mental energy. Retrieved on May 1, 2020, from https://www.washingtonpost. com/lifestyle/2020/04/27/life-lockdown-is-testing-parentsbandwidth-heres-how-protect-your-mental-energy/.

Wallston, K. A. (2015). Control beliefs: Health perspectives. In J. D. Wright (Ed.), International Encyclopedia of the Social \& Behavioral Sciences (2nd ed., 819-821). Elsevier. https://doi.org/ 10.1016/b978-0-08-097086-8.14070-x

Wang, C., Pan, R., Wan, X., Tan, Y., Xu, L., Ho, C. S., \& Ho, R. C. (2020a). Immediate psychological responses and associated factors during the initial stage of the 2019 coronavirus disease (COVID-19) epidemic among the general population in China. International Journal of Environmental Research and Public Health, 17(5), 1729. https://doi.org/10.3390/ijerph17051729.

Wang, C., Pan, R., Wan, X., Tan, Y., Xu, L., McIntyre, R. S., Choo, F. N., Tran, B., Ho, R., Sharma, V. K., \& Ho, C. (2020b). A longitudinal study on the mental health of general population during the COVID-19 epidemic in China. Brain, Behavior, and Immunity, 87, 40-48. https://doi.org/10.1016/j.bbi.2020.04.028.

Wang, K., Goldenberg, A., Dorison, C. A., Miller, J. K., Lerner, J. S., Gross, J. J., \& Psychological Science Accelerator. (2020). A global test of brief reappraisal interventions on emotions during the COVID-19 pandemic. Registered Report. Nature Human Behavior. https://doi.org/10.6084/m9.figshare.12302288.v1.

DNA Web Team (2020, March 29). From travel ban to lockdown, here's a timeline of India's response to the COVID-19 outbreak. Retrieved April 23, 2020, from https://www.dnaindia.com/india/report-fromtravel-ban-to-lockdown-here-s-a-timeline-of-india-s-response-tothe-covid-19-outbreak-2818885

Westerhof, G. J., \& Keyes, C. L. (2010). Mental illness and mental health: The two continua model across the lifespan. Journal of Adult Development, 17(2), 110-119. https://doi.org/10.1007/s10804009-9082-y.

World Health Organization (2020). Mental health and psychosocial considerations during the COVID-19 outbreak, 18 March 2020 (No. WHO/2019-nCoV/MentalHealth/2020.1). World Health Organization.

Xiong, J., Lipsitz, O., Nasri, F., Lui, L. M. W., Gill, H., Phan, L., ... Majeed, A. (2020). Impact of COVID-19 pandemic on mental health in the general population: A systematic review. Journal of Affective Disorders, 277, 55-64. https://doi.org/10.1016/J.JAD. 2020.08.001.

Yeo, S. N., Zainal, H., Tang, C. S., Tong, E. M., Ho, C. S., \& Ho, R. C. (2017). Success/failure condition influences attribution of control, 
negative affect, and shame among patients with depression in Singapore. BMC Psychiatry, 17, 285. https://doi.org/10.1186/ s12888-017-1451-7.

Zhang, S. X., Wang, Y., Rauch, A., \& Wei, F. (2020). Unprecedented disruption of lives and work: Health, distress and life satisfaction of working adults in China one month into the COVID-19 outbreak.
Psychiatry Research-Neuroimaging, 288, 112958. https://doi.org/ 10.1016/j.psychres.2020.112958.

Publisher's Note Springer Nature remains neutral with regard to jurisdictional claims in published maps and institutional affiliations. 